\title{
Effective Area of Graphite Tablets in Amalgam Decomposer*
}

\author{
Fumio Hine and Shiro Yoshizawa
}

The effective area, $\overline{\boldsymbol{S}}_{h}$, of graphite tablets in amalgam decomposer is one of the most important values in designing the packed tower.

The value, $\bar{S}_{h}$, is represented as follows :

$$
\begin{aligned}
& \bar{S}_{h}=\alpha_{h} S_{h} \ldots \ldots \ldots \ldots \\
& m_{h}=\frac{\bar{S}_{h}}{S H}=\frac{\alpha_{h} S_{h}}{S H}
\end{aligned}
$$

where

$$
\begin{aligned}
S_{h} & : \text { Apparent area of tablets }\left(\mathrm{m}^{2}\right) \\
\bar{S}_{h} & : \text { Effective area of tablets }\left(\mathrm{m}^{2}\right) \\
m_{h} & : \text { Effective area per unit volume of tower }\left(\mathrm{m}^{2} / \mathrm{m}^{3}\right) \\
\alpha_{h} & : \text { Coefficient of effective area } \\
S & : \text { Sectional area of tower }\left(\mathrm{m}^{2}\right) \\
H & : \text { Height of tower }(\mathrm{m})
\end{aligned}
$$

Then, the value $m_{h}$ represents theoretically as follows:

(i) Spherical Tablet:

$$
m_{h}=\frac{4 \pi r^{2} \alpha_{h} N}{S H} \times 10^{-6}
$$

where

$$
\begin{aligned}
& r: \text { Radius of tablet }(\mathrm{mm}) \\
& N \text { : Packed number }
\end{aligned}
$$

(ii) Cylindrical Tablet:

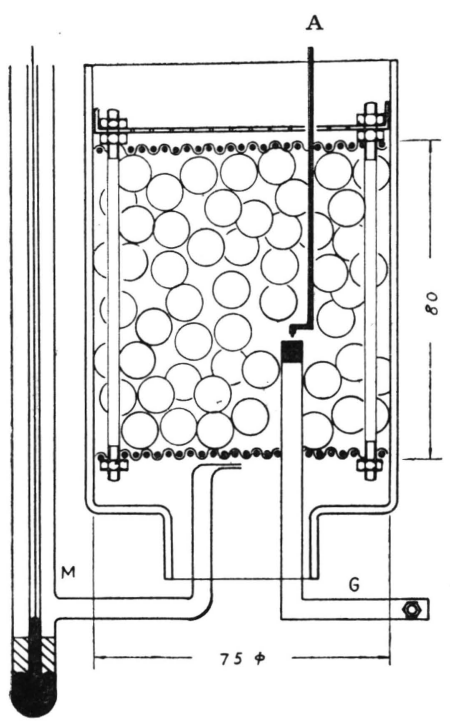

Fig. 1 Amalgam decomposer.

$$
m_{h}=\frac{2 \pi r(r+l) \alpha_{h} N}{S H} \times 10^{-6}
$$

where

$$
\begin{aligned}
& r: \text { Radius of cylinder }(\mathrm{mm}) \\
& l: \text { Height of cylinder }(\mathrm{mm})
\end{aligned}
$$

The decomposition of amalgam is electrochemical, so that, these values, $\alpha_{h}$ and $m_{h}$, are measured by means of electrochemical methods ${ }^{(1)}$.

Fig. 1 shows the amalgam decomposer, and the size of this tower is as follows:

$\begin{array}{lc}\text { Diameter } & 75 \mathrm{~mm} \phi \\ \text { Height } & 80 \mathrm{~mm} \\ \text { Diameter of tablet } & 10 \mathrm{~mm} \phi \\ \text { Packed number } & 420 \text { tabs. } \\ \text { Distributor } & 1.5 \mathrm{~mm} \phi \text { holed plate }\end{array}$
and also the experimental conditions are :

Concentration of caustic soda $20-50 \%$

Concentration of amalgam

$0.03-0.25 \%$

* Studies on Amalgam Decomposition of Alkaline Industry,

** Department of Industrial Chemistry, Kyoto University.

The original written in Japanese can be seen in J. Electrochem. Soc. Japan, 27, (1959). 


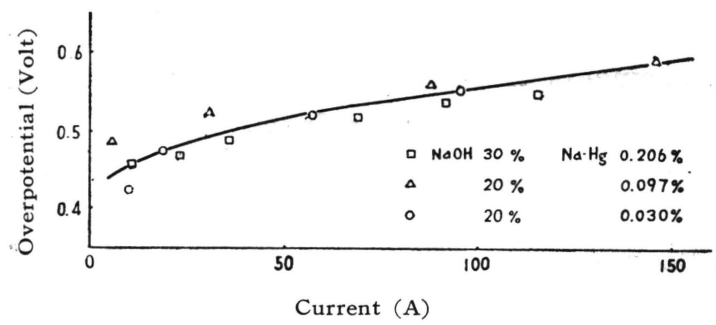

Fig. 2 Hydrogen overpotential in amalgam decomposer.

$\sigma(a)$

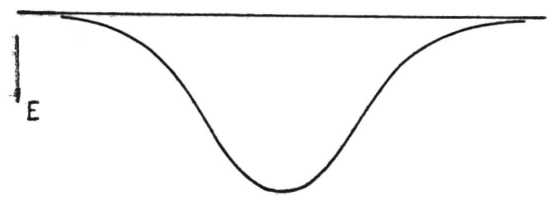

Fig 4 Current distribution in amalgam.

Flow of amalgam

Temperature

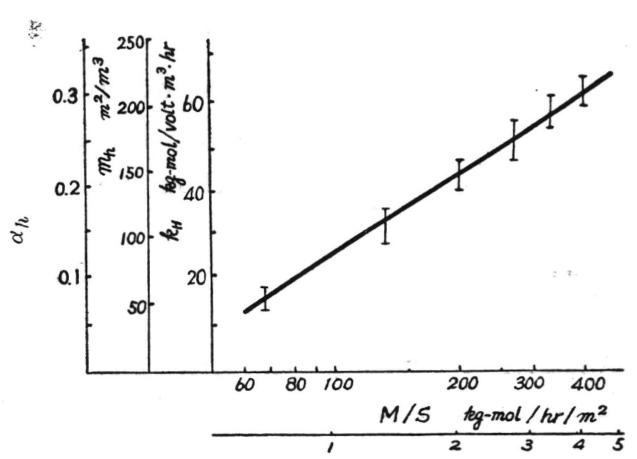

$\left(\times 10^{2}\right) \mathrm{kg} / \mathrm{h}$

Fig. 3 Effective area of amalgam decomposer.

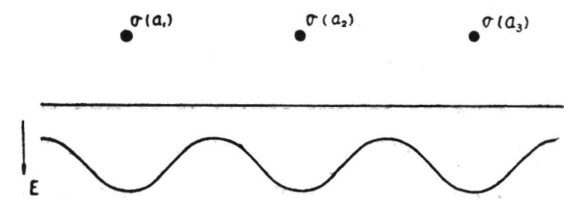

Fig. 5 Current distribution in amalgam.

The hydrogen overpotential at graphite tablets during operation is measured as in Fig. 2, which is referred to $\mathrm{Hg}-\mathrm{HgO}$ electrode.

Both the total current and the overpotential correspond to amalgam flow at lower range. But above $6-6.5 \mathrm{~kg} / \mathrm{min}$, current does not increase more.

Effective area is calculated by the same method of previous paper concerning the shielding effect of evoluting gas at electrode surface ${ }^{(2)}$.

Such deviations of overpotential from theoretical value may be due to irregularity of electrical field as shown in Figs. 4 and 5, and then to shielding effects of evoluting gas and amalgam.

The values, $\alpha_{h}$ and $m_{h}$, are calculated from empirical results, and are represented as Fig. 3. Then, we may conclude that, actual value of $m_{h}$ is $170-200 \mathrm{~m}^{2} / \mathrm{m}^{3}$ on $10 \mathrm{~mm} \phi$ spherical tablets.

(Received August 9, 1958)

\section{Literature :}

(1) F. Hine, S. Yoshizawa, S. Okada, J. Electrochem. Soc. Japan, 27, 134 (1959).

(2) F. Hine, S. Yoshizawa, S. Okada, J. Electrochem. Soc. Japan, 24, 370 (1956). 